\title{
ESTIMATIVA NUMÉRICA: ESTADO DA ARTE
}

\section{ESTADO DA ARTE}

SILVA, Maysa D'avila Barbosa da ${ }^{1}$

SILVA, Sarah Gabriela de Farias ${ }^{2}$

LIMA, Elielson Magalhães ${ }^{3}$

SILVA, Maysa D'avila Barbosa da. SILVA, Sarah Gabriela de Farias. LIMA, Elielson Magalhães. Estimativa Numérica: Estado da arte. Revista Científica Multidisciplinar Núcleo do Conhecimento. Ano 05, Ed. 01, Vol. 03, pp. 107-120. Janeiro de 2020. ISSN: 2448-0959, Link de acesso: https://www.nucleodoconhecimento.com.br/educacao/estimativa-numerica

\section{RESUMO}

O referente estudo trata-se de um artigo no modelo de Estado da Arte ou Estado do Conhecimento e busca sistematizar uma visão geral sobre a aplicação da estimativa numérica no Brasil com foco na educação matemática nos períodos entre o primeiro semestre de 2000 ao primeiro semestre de 2019. Para esse fim, foi realizado uma busca na base de dados Scielo, em canais de eventos brasileiros e selecionados os artigos que tinham alvo central da pesquisa, foram retirados os que não se enquadraram no recorte de critérios pré-estabelecidos, restando um total de 11 artigos para elaboração deste Estado da Arte. Ademais é evidente a escassez de artigos sobre estimativa numérica para educação matemática, sendo este Estado da Arte uma fonte de atualização sobre o que já foi produzido sobre esta temática.

\footnotetext{
${ }^{1}$ Graduanda de Licenciatura Em Matemática.

${ }^{2}$ Graduanda de Licenciatura Em Matemática.

${ }^{3}$ Doutorando Em Educação.
} 
Palavras-chave: estimativa numérica, educação, matemática.

\section{INTRODUÇÃO}

A estimativa numérica, segundo Dowker (1992, p.45), [...] "são suposições razoáveis quanto às respostas aproximadas a problemas aritméticos, sem ou antes de realmente fazer os cálculos". No dia a dia, de forma geral, a estimativa está presente em diferentes situações, desde a realização cálculos rápidos até quantidades aproximadas, sendo utilizada tanto por crianças quanto por adultos (NOGUES; DORNELES, 2018).

O objetivo deste trabalho é esquematizar em forma de "estado da arte" ou "estado do conhecimento" os artigos produzidos no Brasil sobre estimativa numérica com ênfase na educação matemática, no período do primeiro semestre de 2000 à primeiro semestre de 2019 e fornecer uma visão geral sobre esta temática, analisando, entre outros aspectos, os métodos utilizados pelos pesquisadores e público alvo mais frequente.

A partir de um grupo de estudo realizado na universidade, no qual foi proposto pelo orientador uma pesquisa sobre a estimativa numérica. De início, isso serviria para encontrarmos uma linha de base de pesquisa para o trabalho de conclusão de curso. Entretanto, com o passar do tempo, manifestou-se a intenção de mapear o quanto os pesquisadores já haviam percorrido com este assunto, para a partir desse conhecimento, elucidar os diferentes tipos de estimativa utilizados, qual foco da pesquisa e desvelar perspectivas para trabalhos futuros.

As pesquisas denominadas de estado da arte é uma sistematização de um conhecimento específico em um recorte de tempo pré-estabelecido, reconhecendo assim os resultados desta investigação, os temas mais recorrentes, bem como as lacunas existentes (HADDAD, 2002). A compreensão deste tipo de pesquisa é necessária no processo de evolução da ciência, pois permite uma ordenação periódica de um conjunto de informações e resultado já obtidos (SOARES; MACIEL, 2000). 
Considerando a relevância dos estudos sobre a estimativa numérica e também do estado da arte, que além de ser uma fonte de conhecimento é um viés para se utilizar como forma de atualização sobre determinado assunto, buscamos agrupar de forma coesa todos os artigos produzidos sobre essa temática e analisar as diferentes perspectivas abordadas em cada um deles.

\section{A ESTIMATIVA NUMÉRICA}

A estimativa baseia-se em atribuir um valor aproximado, seja na realização de um cálculo, quantia ou grandeza (GIONGO; QUARTIERI; REHFELDT, 2013). É um método para resolver situações no cotidiano, quando existir a necessidade de resolver o problema, então a estimativa é uma alternativa para encontrar o resultado, seja de uma operação ou quando for impossível conhecer o valor exato (AZEVEDO, 1996).

Em algumas situações nota-se a presença da estimativa, como por exemplo, qual é a distância e o tempo da casa do aluno até a escola? Qual o valor gasto em compras diárias? Pelo fato de não saber com precisão exata esses resultados é necessário estimar um valor aproximado. Ao estimar a distância, tempo e o valor, considera-se que são habilidades necessárias no cotidiano (NOGUES; DORNELES, 2018).

À medida que vai sendo utilizada a estimativa, os resultados aproximados aparecem com mais precisão. A utilização dela auxilia nas estratégias, pois o aluno vai planejar alguma estratégia ou método para resolver e assim aproximar do resultado (REYS, 1986). O ensino da matemática deve expandir o pensamento e conhecimento do aluno para que este não fique delimitado no básico, mas tenha oportunidades para expandir seus conhecimentos, observar situações e perceber que a estimativa é necessária. Quando a criança começar a perceber a estimativa no dia a dia, ela terá mais facilidade para aproximar do valor, pois começará a ter mais contato com essa alternativa de aproximação e com isso o conhecimento poderá ser ampliado (MACHADO, 2010). 


\section{MÉTODO}

Esse estudo foi norteado por elementos da pesquisa bibliográfica e do estado da arte, a qual se define como "[...] um instrumento que busca a compreensão do conhecimento sobre determinado tema, em um período de tempo específico e, consequentemente, sua sistematização e análise" (TEIXEIRA, 2006, p. 60).

Foi efetuada uma busca, por meio do descritor ou palavra-chave "estimativa numérica", e foram selecionados os artigos voltados para estimativa numérica com foco na educação matemática.

Os critérios de inclusão foram artigos publicados em base de dados e em anais de eventos brasileiros, no período de publicação entre o primeiro semestre de 2000 e o primeiro semestre de 2019. Assim, as buscas desses periódicos foram em: Scielo, Encontro Nacional de Educação Matemática - ENEM (XI e XII), VI Congresso Internacional de Ensino de Matemática e Revista de Estudos e Pesquisas em Educação.

\section{RESULTADOS E DISCUSSÕES}

Inicialmente, foi encontrado um total de 33 artigos com o descritor "estimativa numérica" na base de dados Scielo. Diante desses processos, foram descartados os que não contemplavam os critérios de inclusão, restando assim 3 artigos. Nos demais foram realizadas uma análise detalhada nos artigos dos respectivos eventos e coletados os que se enquadraram. No Encontro Nacional de Educação Matemática, foram encontrados cinco artigos referente a temática aqui abordada, dois artigos no VI Congresso Internacional de Ensino da Matemática e apenas um, na Revista de Estudos e Pesquisas em Educação.

Dividimos os artigos encontrados em cinco categorias, sendo elas: E1 referente à reta numérica; E2 áreas e medidas, E3 quantitativo, E4 aritmética e E5 teórico. Alguns artigos se encaixam em mais de um tipo de categoria. 
Quadro 1: Os resultados referentes a cada tipo de investigação de estimativa

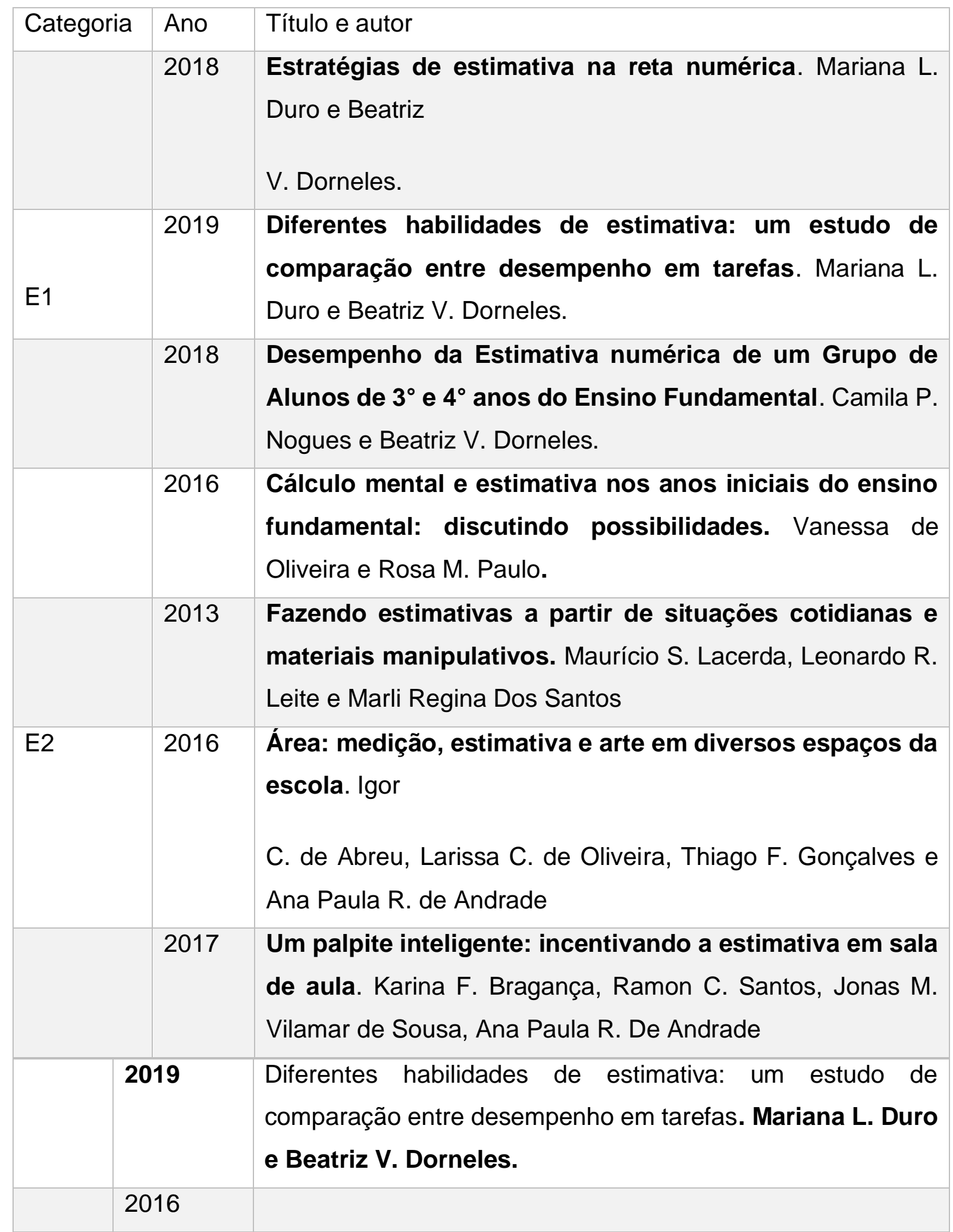


E3

\begin{tabular}{|l|l|}
\hline 2017 \\
\hline 2016 \\
\hline
\end{tabular}

2018

E4

E5 2013
Desenvolvimento da estimativa numérica e desempenho em aritmética em crianças: um estudo comparativo entre tarefas. Mariana L. Duro e Camila P. Nogues

Um palpite inteligente: incentivando a estimativa em sala de aula. Karina F. Bragança, Ramon C. Santos, Jonas M. Vilamar de Sousa, Ana Paula R. De Andrade

O uso da estimativa nos anos iniciais do ensino fundamental. Vanessa de Oliveira, Raissa S. Sampaio e Carolina C. Batista

\section{O uso da estimativa em tarefas numéricas com alunos do} $3^{\circ}$ ano do ensino fundamental na perspectiva do sentido numérico. Giovana Sander; Nelson Pirola e Joana Brocado 2017 Um palpite inteligente: incentivando a estimativa em sala de aula. Karina F. Bragança, Ramon C. Santos, Jonas M. Vilamar de Sousa, Ana Paula R. De Andrade

\section{Problematizando o uso da estimativa em aulas de} matemática da escola básica. leda Maria Giongo, Marli Teresinha Quartieri e Marcia Jussara H. Rehfeldt

Fonte: Elaboração própria

Na primeira categoria $E 1$, os três artigos utilizaram o método da reta numérica para analisar o desempenho da estimativa nas turmas do ensino fundamental I e II. Foram distribuídos para os alunos a reta numérica em escolas diferentes nas quais as autoras falaram o número que eles deveriam estimar sobre a reta. Duro e Dorneles (2018), abordou esse modo de estimativa em um grupo de 30 alunos do $2^{\circ}$ ao $6^{\circ}$ ano do ensino fundamental, foram utilizadas três escalas diferentes $(0-10,0-20,0-100)$ de retas e os números escolhidos pelas autoras foram 4,7,9,17,25,49,78,95. Nesta tarefa, os resultados mostraram que os alunos progrediram em estratégias de estimativa de acordo com a idade, pois as estratégias mais simples e, em contrapartida, menos precisas, foram usadas pelos alunos dos primeiros anos do ensino fundamental e os alunos mais velhos usavam estratégias mais elaboradas. 
No segundo artigo, Duro e Dorneles (2019), utilizaram dois tipos de estimativa, realizando uma comparação entre essas atividades. Estas, tiveram como público alvo os alunos do $5^{\circ}$ e $6^{\circ}$ do ensino fundamental, realizando em uma escola pública e outra em uma escola particular de Porto Alegre. Participaram desses testes um total de 284 alunos.

- Na primeira tarefa, foram apresentadas matrizes com escalas diferentes $10 \times 1$ (E10), 10x2 (E20) e 10x10 (E100), na qual será apresentado mais detalhadamente no tipo de agrupamento

- Na segunda tarefa, os alunos tinham que estimar um número aleatório em retas numéricas com escalas diferentes, no qual apresentavam marcações no ponto inicial e no ponto final da reta. As escalas escolhidas foram 0-10, 0-20 e 0-100.

O estudo constatou, que a precisão obtida na primeira tarefa é superior a segunda tarefa, pois, segundo as autoras, a reta numérica é pouco utilizada no Brasil, enquanto a quantificação de elementos é mais abrangente, principalmente nos anos iniciais.

O último artigo desse grupo E1, Nogues e Dorneles (2018) tiveram como foco avaliar 143 alunos das turmas do $3^{\circ}$ e $4^{\underline{0}}$ anos do ensino fundamental de uma escola municipal de Porto Alegre/ RS, desenvolvendo duas tarefas de estimativa na reta numérica com escala de 0-100, a número-posição e a posição-número. Na primeira atividade de número-posição, a pesquisadora falava um número e os alunos tinham que indicar o número na reta numérica, e na outra seria justamente ao contrário, estaria na reta numérica a marcação e os alunos tinham que estimar qual número aproximadamente seria.

O resultado mostrou que o desempenho do $4^{\circ}$ ano foi superior ao $3^{\circ}$ ano e que a representação numérica apresenta um comportamento mais linear no $4^{\circ}$ do que $3^{\circ}$ ano. Com os resultados obtidos, a tarefa posição-número apresentou resultados mais precisos. 
Figura 1: Referente ao agrupamento E1.

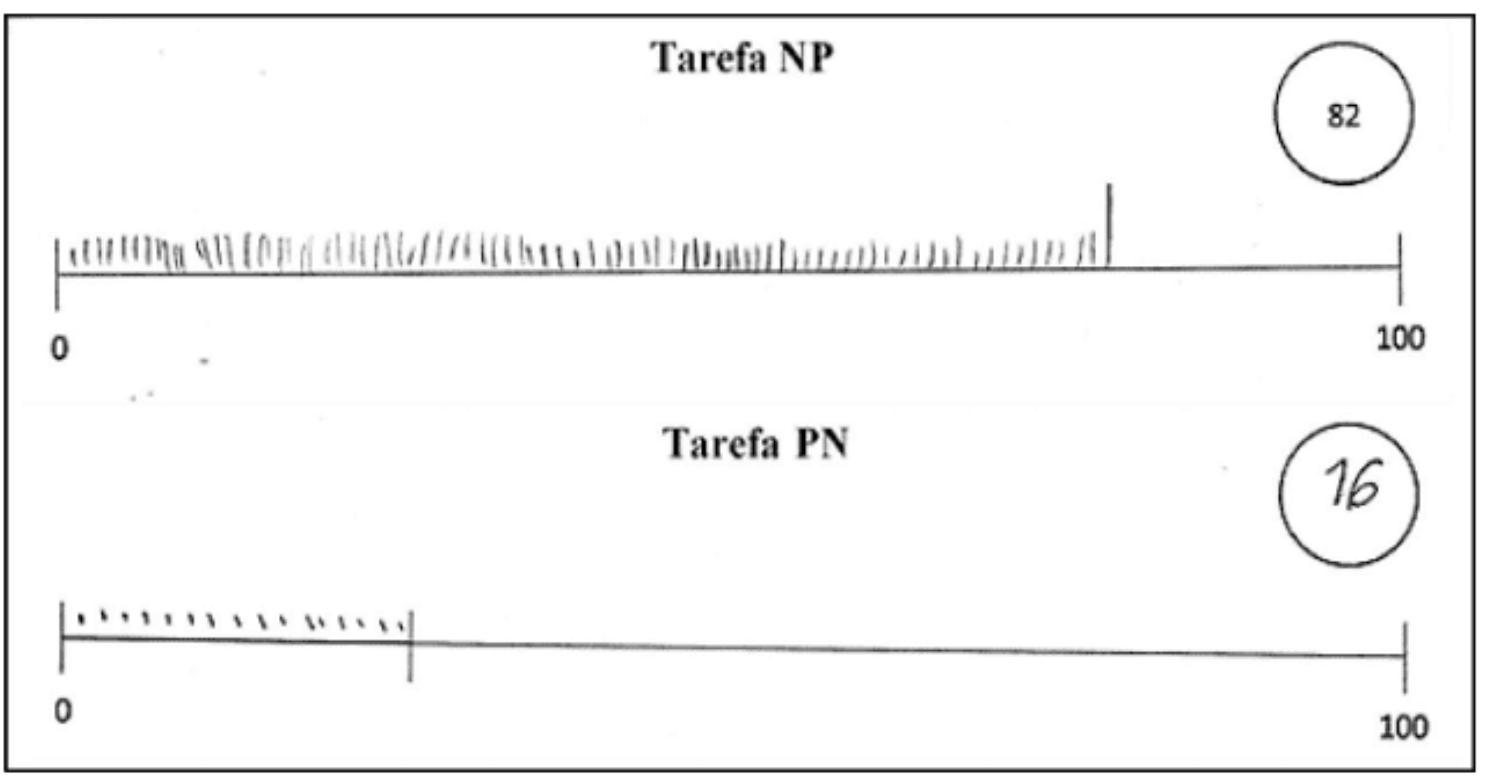

Fonte: Nogues e Dorneles (2018)

$\mathrm{Na}$ segunda categoria $\mathrm{E2}$, obtiveram quatro artigos relacionados com áreas e medidas. Tendo como foco a estimativa, ou seja, foram abordadas situações envolvendo a estimativa nas aulas de matemática. Oliveira e Paulo (2016), tiveram como proposta estimar o comprimento de alguns objetos da sala de aula. Esta atividade foi realizada com a turma do $5^{\circ}$ ano. A proposta da atividade ficou conhecida como o "Jogo da Estimativa", tendo como objetivo desafiar a outra dupla para estimar algum objeto da sala de aula. Após o valor estimado, aos alunos mediram utilizando a régua ou a fita métrica para conferir e os pontos eram de acordo com a diferença entre o valor estimado e o valor real do objeto. Os alunos precisavam ter um conhecimento prévio sobre medidas, para terem uma maior precisão nos resultados.

O segundo artigo do E2, Lacerda; Leite e Santos (2013), foram relatadas atividades desenvolvidas por alunos do $9^{\circ}$ ano do Ensino Fundamental e obtiveram resultados diferentes. A primeira atividade contou a construção do metro quadrado, tendo como objetivo observar se os alunos apresentam entendimento sobre medidas. Com a construção do metro, os alunos encaixam os metros quadrado e mediram a sala de aula e, com isso, perceberam quantos metros a sala tinha. Apenas dois alunos 
conseguiram obter o valor exato. Logo após, construíram seis quadrados e a partir dele construíram um metro cúbico.

E para finalizar, os alunos responderam algumas questões sobre área e volume. Contudo, os alunos não apresentaram um bom desempenho. Vale salientar a importância de abordar a estimativa em sala de aula, com atividades do dia a dia, possibilitando os alunos terem um domínio maior sobre a estimava e os resultados estimados.

No artigo produzido por Abreu et al. (2016), a experiência foi aplicada com uma turma do $7^{\circ}$ ano. A proposta contou com 5 atividades e com duas partes, a qual contavam com slides, atividades em sala de aula e no pátio da escola. Cada uma das atividades foram realizadas de formas diferentes e durante a aplicação foram observados e coletados dados, sendo eles: observação, resposta dos alunos nas atividades propostas e anotações descritiva. A primeira atividade foi uma comparação entre as unidades de área diferentes. Na segunda atividade, os alunos estimaram o valor da área da mesa e logo após mediram a área da superfície da mesa com uma das medidas. A terceira tarefa foi parecida com a segunda, porém foi feita em uma superfície maior e foi utilizado o pátio da escola para representação das figuras.

A quarta tarefa contou com a estimativa dos alunos em relação a uma área da superfície e foram utilizados o metro quadrado para medir a área de uma superfície relacionada com as dimensões (largura e comprimento). Na quinta atividade, os alunos desconstruíram a imagem associada a cada área diferente e montaram outras figuras com as diversas partes. Conclui-se que a terceira e a quarta atividade tiveram os resultados mais satisfatório dentre todas as tarefas realizadas, porém no geral os alunos não apresentaram um bom desempenho.

A pesquisa feita por Bragança et al. (2017), relatou uma atividade referente a este tipo de agrupamento que se chamava "Momento da medição", que consistia na apresentação de três sólidos vazios de formas geométricas diferentes e de três garrafas cheias de água. $O$ foco da atividade era que os alunos conseguissem estimar qual volume de água era correspondente a qual sólido geométrico. Segundo os 
autores, mesmo diante da empolgação e interesse dos participantes, eles não obtiveram bons resultados com as estimativas.

Figura 2: Referente ao agrupamento E2.

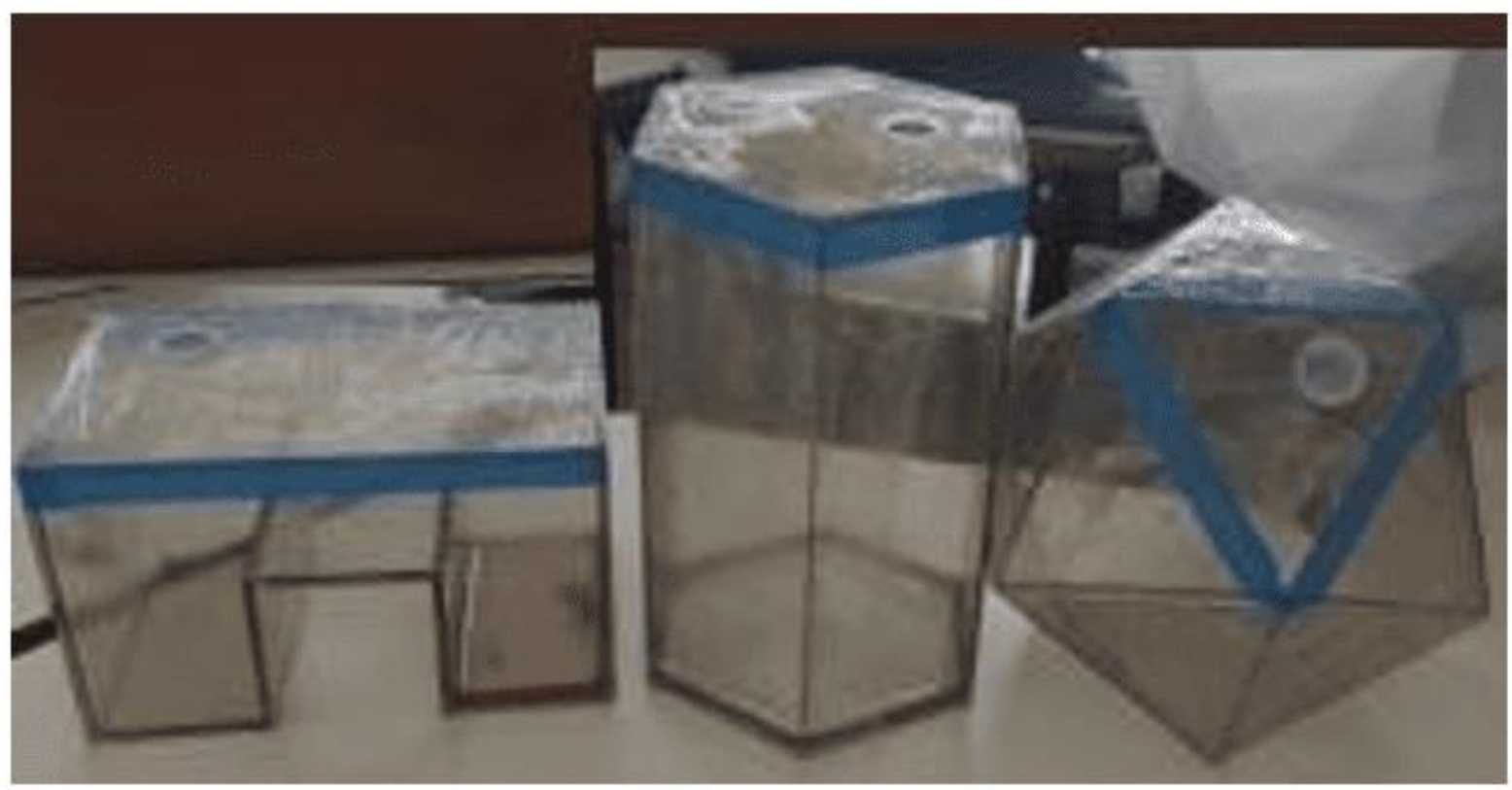

Fonte: Bragança et al. (2017)

No terceiro tipo de categoria E3, encontramos os artigos referentes à estimativa de quantidade, sendo o primeiro deles de Duro e Dorneles (2019). Este artigo teve dois tipos de estimativa usadas, a qual uma delas já foi descrita no agrupamento de reta numérica. A tarefa de estimativa por quantidade consistia em apresentar aos alunos matrizes com escalas diferentes, que foram estruturadas e organizadas pelas pesquisadoras e fundamentava-se em estimar um valor ao conjunto de pontos que cada matriz possuía. Os alunos tinham segundos diferentes para cada uma das matrizes apresentadas e respondiam no caderno a quantidade estimada que considerassem mais adequada. Como o artigo tinha o foco de comparar as duas estimativas utilizadas, pôde-se concluir que a estimativa por quantidade teve o melhor desempenho dos alunos do que a estimativa de reta numérica, embasados na suposição para este resultado de que a quantificação de elementos é bastante propagada no ensino fundamental, principalmente nos anos iniciais. 
O artigo de Nogues e Dorneles (2018), também tem como uma das estimativas aplicadas o uso da estimativa quantitativa, além da estimativa aritmética. O público alvo foram os alunos do $5^{\circ}$ e 6으 de uma escola municipal de Porto Alegre. Participaram um total de 166 alunos. A tarefa consistia em realizar a estimativa das quantidades de pontos, de mesma cor e tamanho, que foram distribuídos em matrizes quadriculadas. Foram distribuídas em diferentes tipos, aglomeradas ou espaçadas, as matrizes variavam entre dez, vinte e cem pontos.

De modo geral, os alunos apresentaram maior desempenho nas atividades com os itens aglomerados e tiveram um desempenho inferior quando foram apresentados de maneira espaçada. Além disso, as estimativas são mais precisas em função da idade e experiência, segundo as considerações obtidas pelas pesquisadoras.

O último artigo que aborda o modo de estimativa por quantidade foi de Oliveira e Paulo (2016). Nesta pesquisa, foram também utilizados o modo de estimativa por aritmética e medição, que estão detalhados nos respectivos tópicos. Enfatizando as quatro tarefas que manusearam com este agrupamento, foram elas: imagens na tela, objetos no pote, desafio das bolinhas e poema. Esta atividade se deu na turma do $9^{\circ}$ ano do ensino fundamental e a turma foi dividida em grupos para realização das tarefas.

- Imagens na tela: foram apresentados quatro slides com representação de pessoas e os grupos deveriam estimar a quantidade presente em cada imagem. Tinha alguns segundos para cada grupo

- Objetos no pote: foram expostos dois potes em tamanho distintos, cheios de doces, no qual os alunos tinham que estimar a quantidade mais próxima de cada um

- Desafio das bolinhas: foi proposto nesta atividade estimar a quantidade de pontos em uma imagem, os alunos tinham um tempo limite

- Poema: os pesquisadores fizeram uma leitura de um texto e os alunos deveriam estimar a quantidade de vezes que determinada palavra era

Pode-se concluir, segundo os resultados da pesquisa, que a reunião de todas as tarefas despertou nos alunos um interesse e uma empolgação durante realização das 
atividades e os autores afirmaram a necessidade de colocar em prática atividades referentes a estimativa numérica em sala de aula para as habilidades serem aperfeiçoadas.

Figura 3: Referente ao agrupamento E3.

\begin{tabular}{|c|c|c|c|c|}
\hline Apresentação & & (4) & 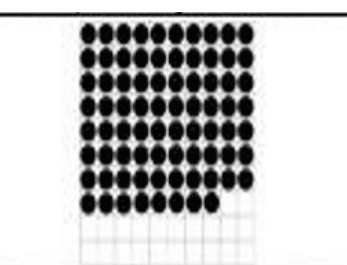 & 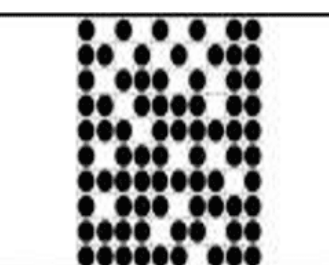 \\
\hline $\begin{array}{l}\text { Tipo de } \\
\text { Atividade }\end{array}$ & $\begin{array}{c}\text { Vazia } \\
\text { (0 elementos) }\end{array}$ & $\begin{array}{c}\text { Cheia } \\
\text { (100 elementos) }\end{array}$ & $\begin{array}{l}\text { Quantidade próxima a } \\
3 / 4 \text { da matriz } 10 \times 10 \text {, } \\
\text { com itens aglomerados }\end{array}$ & $\begin{array}{l}\text { Quantidade próxima a } \\
3 / 4 \text { da matriz } 10 \times 10 \text {, } \\
\text { com itens espaçados }\end{array}$ \\
\hline
\end{tabular}

Fonte: Nogues e Duro (2016)

Também foram encontrados artigos que relacionam a estimativa com a aritmética, que agrupamos e denominamos E4, sendo de Oliveira V.; Sampaio R. S.; Batista C. C.; (2016), uma atividade desenvolvida com alunos do $5^{\circ}$ ano. Foram desenvolvidas duas atividades sobre a estimativa numérica relacionadas com a aritmética. Tendo como objetivo principal identificar, analisar e proporcionar o raciocínio dos alunos, pois possibilita que os alunos pensem e argumentem sobre as escolhas que serão realizadas durante a atividade. Uma das atividades realizadas foi denominada como "o mais perto possível", ou seja, com duas cartas diferentes e de 0 a 9 , e tendo como objetivo formar o número mais próximo possível.

A sala foi dividida em grupos e tinham duas opções de formar os números e após a formação, o grupo justificava o motivo de escolher esse número e também explicavam o porquê de não ter escolhido o outro número. A outra atividade é caracterizada pela aritmética também, pois proporciona uma comparação entre a soma ou a subtração, e esta atividade foi denominada "maior ou menor". Também foi necessário justificar a resposta. Observando os resultados, percebe-se que as atividades foram desenvolvidas por meio de estratégias de aproximação. 
O outro artigo relacionado com a estimativa de aritmética, tendo como autores Sander, Pirola e Brocado (2018), trata-se de uma investigação realizada com alunos do $3^{\circ}$ ano do Ensino Fundamental I e participaram 12 escolas públicas (estaduais e municipais) com o total de 351 alunos. Também foi utilizada duas atividades: "Quantos anos João viveu?" e "A compra de Marisa". Tendo como objetivo observar a resposta dos alunos em relação ao contexto e ao cálculo mental. Através dos dados, nota-se que a estimativa é pouco usada e com isso acarretou em um resultado não muito desenvolvido.

Bragança et al. (2016) em uma das atividades realizadas abordam a aritmética. As atividades foram realizadas com alunos $9^{\circ}$ ano e para organizá-las foram analisados alguns dados, sendo eles: observação, anotação e as repostas dos alunos. A atividade foi dividida em três etapas: na primeira e a segunda parte foram entregues fichas para que os alunos anotassem os resultados de duas atividades realizadas, sendo elas: Imagens na Tela e Jogo de antecipação. A primeira atividade, imagens na tela, apresentam quatro slides contendo imagens de pessoas, esta atividade tem como objetivo estimar a quantidade de pessoas presentes nas imagens. A segunda atividade, jogo da antecipação, contendo dez slides e cada um apresentam uma operação de soma ou uma operação de subtração, o objetivo é que os alunos estimem os resultados de cada operação presente em cada um dos slides. Na terceira parte foram apresentadas slides mostrando a importância da estimativa.

Os resultados desta atividade mostram que a estimativa não é frequente, porém os alunos tiveram muito interesse e foram competitivos e não apresentaram um bom desempenho na atividade, mas os resultados foram satisfatórios. 
Figura 4: Referente ao agrupamento E4.

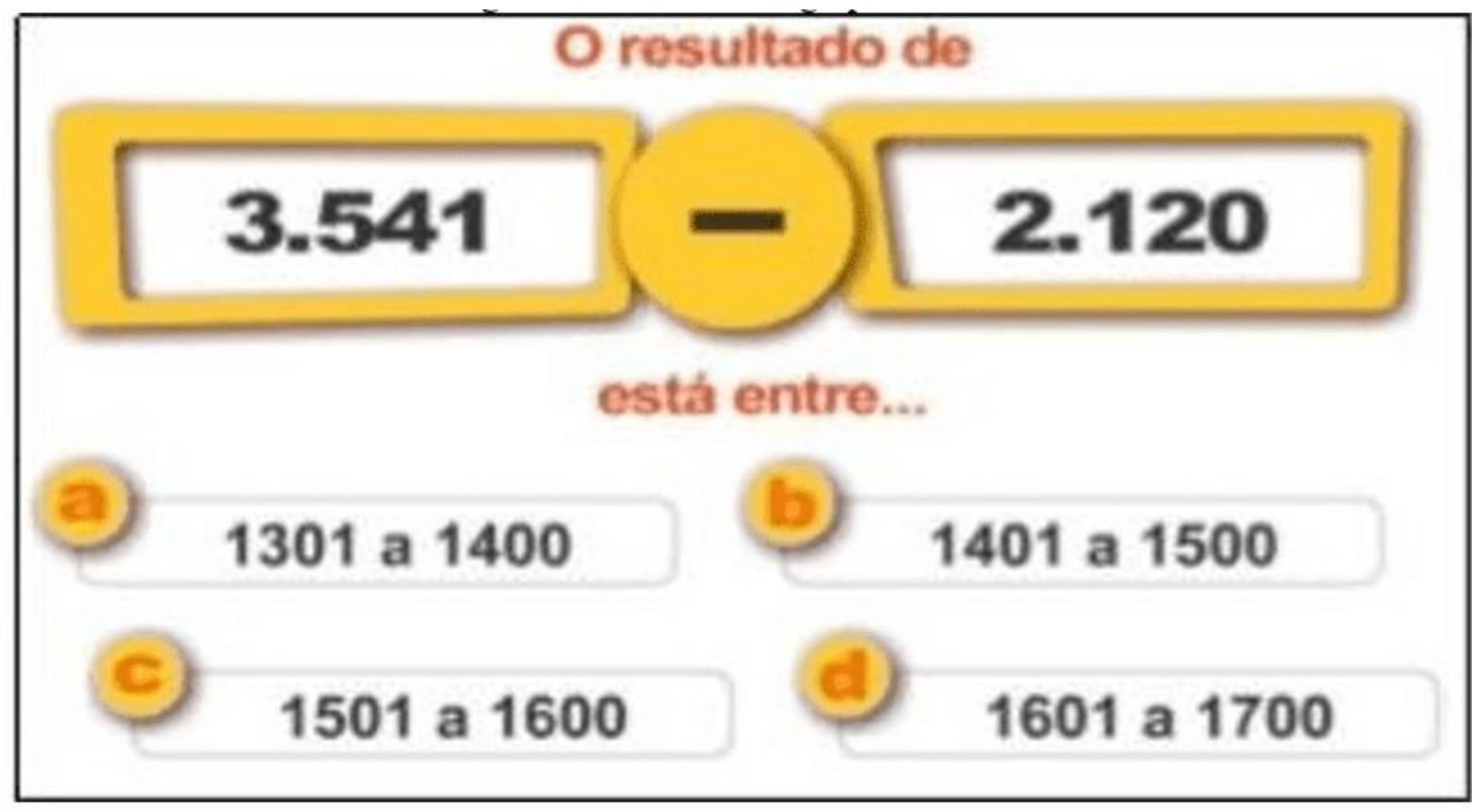

Fonte: Elaboração de Bragança et al. (2016)

O agrupamento E5 denominado teórico, teve apenas um artigo associado a este tópico, sendo produzido por Giongo, I. M.; Quartieri, M. T.; e Rehfeldt, M. J. H. (2013). Foi dentre todos os artigos aqui apresentados o que teve a proposta mais diferente e o grupo-alvo totalmente oposto com os demais. Teve como foco principal oferecer um curso de formação continuada para docentes da educação básica do município de Lajeado- Rio grande do Sul sobre teoria da estimativa numérica, bem como toda importância para aplicação em sala de aula e acoplado com a parte prática. O curso tinha a carga horária de 40 horas e participaram deste evento 40 professores tanto dos anos iniciais como professores de matemática.

Durante o curso teve diversos exemplos práticos do uso estimativos e vários relatos de dificuldades por parte dos docentes, intensificando a necessidade de ter cursos para instruir e capacitar professores para assim poder aplicar esse tipo de atividade em sala de aula.

Como tarefa final, os professores ficaram com a proposta de desenvolver alguma atividade de estimativa com seus alunos e fazer um relatório descrevendo todo o 
processo, bem como as análises observadas por eles em relação ao desempenho dos estudantes. E neste último encontro foi um encontro de muitas experiências compartilhadas. Como conclusão deste curso, os professores de forma unânimes, expressaram o quanto foi construtivo o curso, toda teoria trabalhada e toda a parte de prática, além dessa oportunidade de aplicar com seus alunos.

\section{CONSIDERAÇÕES FINAIS}

O presente estudo traz a possibilidade de despertar o saber acerca da estimativa numérica e sendo uma alternativa para aplicação em sala de aula. Nos onze artigos analisados o público alvo foram os alunos do ensino fundamental I e II, estudantes de graduação e professores. Os trabalhos foram mais frequentes com os alunos do ensino fundamental I, especialmente os estudantes do $5^{\circ}$ ano que esteve presente em cinco experiências de estimativa numérica.

É notória a importância de estudos relacionados a estimativa numérica, pois diante da carência de trabalhos direcionados nesta área, este artigo serve como fonte de atualização e alimentação para pesquisadores conhecer o que já foi produzido, no Brasil, e a partir disto mapear alguma linha de pesquisa como forma de estímulo de novas pesquisas.

\section{REFERÊNCIAS}

ABREU C. I. et al. Área: Medição, estimativa e arte em diversos espaços da escola. ENCONTRO NACIONAL DE EDUCAÇÃO MATEMÁTICA, 12., 2016. São Paulo. Anais[...]. $\quad$ São $\quad$ Paulo, $2016 . \quad$ Disponível em: http://www.sbembrasil.org.br/enem2016/anais/pdf/5580_2916_ID.pdf. Acesso em: 23 de set. de 2019.

AZEVEDO, M. O. A aprendizagem da estimação matemática: um estudo no $2^{\circ}$ ciclo. Dissertação de mestrado. Lisboa: Universidade Nova de Lisboa. 
BRAGANÇA F. K. et al. Um palpite inteligente: Incentivando a estimativa em sala de aula. In: CONGRESSO INTERNACIONAL DE ENSINO DA MATEMÁTICA, 7, 2017. Canoas- RS. Anais [...]. Canoas, 2017. p. 1-10.

DOWKER, A. Computational Estimation Strategies of Professional Mathematician. Journal for Researching Mathematics Education, 23(1), p. 45-55, 1992.

DURO M. L.; DORNELES, B.V. Diferentes habilidades de estimativa: um estudo de comparação entre desempenho em tarefas. Ciênc. Educ., Bauru, v. 25, n. 1, p. 43-56, 2019.

DURO M. L.; DORNELES, B.V. Estratégias de estimativa na reta numérica. Educar em Revista, Curitiba, Brasil, v. 34, n. 71, p. 205-221, set./out. 2018

GIONGO, I. M.; QUARTIERI, M. T.; REHFELDT, M. J. H. Problematizando o uso da estimativa em aulas de Matemática da Escola Básica. ENCONTRO NACIONAL DE EDUCAÇÃO MATEMÁTICA. 11., 2016. Curitiba. Anais [...]. Curitiba, 2016. Disponível em: http://sbem.iuri0094.hospedagemdesites .ws/anais/XIENEM/pdf/1099_200_ID.pdf. Acesso em: 27 de set. de 2019.

HADDAD, S. Juventude e Escolarização: uma análise da produção do conhecimento. Brasília: MEC/Inep/Comped. 2002. (Série do Estado do conhecimento $\mathrm{n} \cap 8$ ).

LACERDA M. S.; LEITE R. L.; SANTOS R. M. Fazendo estimativas a partir de situações cotidianas e materiais manipulativos. ENCONTRO NACIONAL DE EDUCAÇÃO MATEMÁTICA, 11., 2013. Curitiba. Anais [...]. Curitiba, 2013. Disponível em:

http://sbem.iuri0094.hospedagemdesites.ws/anais/XIENEM/pdf/2614_1482_ID.pdf. Acesso em: 20 de set. de 2019. 
LINK, T., NUERK, H., MOLLER, K. (2014). On the relation between the mental number line and arithmetic competencies. The Quarterly Journal of Experimental Psychology, 67(8), 1597-1613.

MACHADO, I. Algumas dificuldades do Ensino da Matemática na $7^{\circ}$ série do Ensino Fundamental. 2010. Disponível em: http:// www.ucb.br/sites/100/103/TCC/12005/lvete alvesMachado.pdf. Acesso em: 25 de agosto de 2019.

NOGUES C. P.; DORNELES, B.V. Desempenho da Estimativa numérica de um Grupo de Alunos de $3^{\circ}$ e $4^{\circ}$ anos do Ensino Fundamental. Bolema, Rio Claro (SP), v. 32, n. 60 , p. $156-171$, abr. 2018.

NOGUES, C. P.; DURO M. L. Desenvolvimento da estimativa numérica e desempenho em aritmética em crianças: um estudo comparativo entre tarefas. ENCONTRO NACIONAL DE EDUCAÇÃO MATEMÁTICA, 12., 2016. São Paulo. Anais[...]. São Paulo, 2016. Disponível em: http://www.sbem.com.br/enem2016/anais/pdf/71 05_3110_ID.pdf. Acesso em: 30 de set. de 2019.

OLIVEIRA, V.; PAULO M. R. Cálculo mental e estimativa nos anos iniciais do ensino fundamental: discutindo possibilidades. Perspectiva da Educação Matemática- INMA/UFMS - v.9, n.21- Seção Temática. 2016.

OLIVEIRA V.; SAMPAIO R. S.; BATISTA C. C. O uso da estimativa nos anos iniciais do ensino fundamental. ENCONTRO NACIONAL DE EDUCAÇÃO MATEMÁTICA, 12., 2016. São Paulo. Anais[...]. São Paulo, 2016. Disponível em: http://www.sbembrasil.org.br/enem2016/anais/pdf/6275_2741_ID.pdf.Acesso em: 25 de set. de 2019.

REYS, B. J. Teachinng Computational: Concepts and strategies. In: SHOEN, H. L.; ZWENG, W. J. (Eds). Estimation and mental computation, VA: National Concil of Teachers of Mathematics, p. 31-44, 1986. 
SANDER, G.; PIROLA, N.; BROCADO, J. O uso da estimativa em tarefas numéricas com alunos do $3^{\circ}$ ano do ensino fundamental na perspectiva do sentido numérico. Instrumento: R. Est. Pesq. Educ., Juiz de Fora, v. 20, n. 2, jul./dez. 2018. SOARES, M. B.; MACIEL, F. Alfabetização. Brasília: MEC: Inep, 2000.

TEIXEIRA, C. R. O "estado da arte": a concepção de avaliação educacional veiculada na produção acadêmica do programa de pós-graduação em educação: currículo (1975- 2000). Cadernos de Pós-Graduação: educação, São Paulo, v. 5, n. 1, p. 59-66, 2006.

Enviado: Outubro, 2019.

Aprovado: Janeiro, 2020. 